\title{
REFLECTION
}

\section{Measuring Up: Musings of a Family Doctor on the Employee Time Clock}

\section{Ruth Kannai, MD}

Department of Family Medicine, Hadassah School of Medicine, Hebrew University, Jerusalem, Israel
Conflicts of interest: author reports none.

\section{CORRESPONDING AUTHOR}

Ruth Kannai, MD

6B Apt 2 Reuven St

Bet Shemesh, Israel 99544

rkannai@gmail.com

\begin{abstract}
Recently, at the health maintenance organization (HMO) where I work, they introduced an employee time clock. As in many other workplaces, doctors across the country are now obligated to punch the clock at the beginning and end of their workday. This is the final act in an ongoing attempt to enhance management of doctors' schedules: limit nonurgent appointments to 10 minutes, define planned or urgent home visits, and control a physician's time, as well as managerial and clinical decisions. In this story I describe a day in the life of a family doctor, a salaried employee at a large HMO where there is now a time clock. I provide details on how the introduction of the clock influences small everyday clinical decisions that potentially affect the quality and depth of treatment while sharing the internal dialogue that accompanies me as I reaffirm my professional integrity again and again with each hastened visit. I also bring the internal dialogue of 2 of my patients, to illustrate the emotional world on the other side of these 10-minute interventions.
\end{abstract}

Ann Fam Med 2013;477-480. doi:10.1370/afm.1540.

Not everything that matters can be measured, and not everything that can be measured, matters.

Anonymous

\section{INTRODUCTION}

$\mathrm{T}$ The pressure of time is a universal concern for doctors. The introduction of a time clock that a doctor must punch into at the beginning and end of the work day is a significant act on the employer's part to control the physicians' schedule. Many doctors oppose the time clock for various reasons. Such a change was secured in the new doctor's agreement signed in my country as part of a series of actions intended to strengthen public health services. I believe that the values of service, listening, compassion, and simply being there for the patient are sometimes harmed by the action of punching the time clock. The struggle between being efficient and being attentive is described in this workday diary of a family physician, where the time clock is an additional complicating player.

\section{7:58 - The Day Begins}

Whew, what luck, I made it on time! I made everyone's sandwiches, packed them in the right bags, dropped the little one outside school at 7:35 before the gates even opened. Traffic was on my side.... I got to the clinic on time and managed to enter the building without being delayed by Moshe who was outside smoking to help him relax before his blood test, which will once again prove his diabetes is unbalanced and his lipids are horrendous.

I almost make it to the time clock when the nurse calls me to a room to take blood from a newborn who was just released from the hospital and whose thyroid function test was abnormal.

I throw my bag in the corner of the treatment room, rub my cold hands together, and approach my tiny victim's soft neck. 
His mother is unrelenting, repeatedly questioning whether it is absolutely necessary to take blood from her baby's neck. I sit her down, patiently explaining this is a large vein that protrudes upon crying and it will not hurt him more than a tummy ache does when he's hungry.

I miss the first time...cotton swabs, baby over the shoulder, softly pat his back...sorry, I apologize... another try, there's another side. I take off my sweater; it's so hot in here....

The baby doesn't stop crying. On my next attempt I succeed, the blood pumps into the tube with each ensuing cry. I grab my bag and continue to my office. "Don't forget to check in" the secretary reminds me, aware of my weakness.

Oops, it's 8:12. I just swiped. Shucks.

\section{8:14 - Martha Silverman, Age 78 Years, Waits Outside My Door}

Martha: I've been sitting here since 7 AM. I know, the nurse told me I don't have an appointment and the list is full until 11:40, but I'm sick and I'm not giving in. I came here first. I got up at 5 AM today with heart palpitations and I waited for the first ride I could get with working parents to the nursery right near the clinic. I'm 78 years old and I know my body well enough. I have my usual pains in my knees, shoulder, lower back; and the heart palpitations; and the heart itself that hurts when I go uphill and my legs....ah, my legs will be the death of me...every Sunday morning I have a new symptom to present to our nice doctor and sometimes on Thursdays too. As for the appointment, here's the thing-I don't really manage well with the "press 2 and wait" business on the phone- "Your call is important to us," and the annoying music with the advertisements for vaccinations for people going abroad to places I never have and never will visit. In any case, they always place me as "urgent." The doctor is a little impatient but she always receives me with a smile and some comforting words. When she's on vacation I don't come to the clinic; I know I have no chance. My children live in the village, but they rush off to work every morning, so I have to make my way here hitchhiking with the hope that I won't have to walk from the junction in the rain or heat. On the way back I always manage... one of the young people who comes here with their kids always takes me home. I'm in no rush.

\section{8:40}

The woman with the baby enters. She rightly claims that her appointment was scheduled for 8:10. She's a working woman and needs to distribute her 4 children in day care-that is, if I approve they can be put there. She's already used up all of her family sick days for the year and it's only March... and her boss is already losing patience. Perhaps because I had mercy on her and gave her sick days with "fatigue" as the diagnosis once or twice...just 1 or 2 days rest from her hard work....
The 4 year old has a runny nose and a cough: "Just listen to her lungs for a moment." The 3 year old touches her ear, the 18 -month old is recuperating from an ear infection. "Just take a peek to see everything's okay.... and if you don't mind, she's also not eating anything. Just cocoa milk and pasta...the 4-month old is gaining weight, thank God, but maybe you can just look into her ears for a second because I'm afraid she may have contracted the ear infection from the 3-year old." She gets offended when I ask her why she didn't schedule 4 appointments. She's embarrassed to say that her mother-in-law asked her-because she's already going to the doctor-to bring her prescription renewals for the next 3 months.

\section{9:02}

I've already spent 22 minutes with the mother of 4 who made only a single appointment. But after all, she had waited 30 minutes outside because of the blood test and the 4 nice elderly ladies who defined themselves as "urgent" and yet another patient who "just ran out of his prescriptions" and has been 2 days without insulin.

She asks for some blood tests for herself because she's exhausted all the time. I know I can choose the easy route: recommend a blood count and thyroid test, maybe some $B_{12}$ if she insists.

I manage to gather myself, however, and remind myself I am a family physician, dealing with the entire biopsychosocial aspects of family life, and I ask the question I know will take at least another precious 10 minutes: "By the way, what form of contraception have you been using since the birth of the little one?" Once again, she tells me she is relying on breastfeeding as birth control (which is how she got pregnant with the 4-month old, the 18-month old, and the 3-year old...) and yes, she is anxious about another pregnancy and is exhausted with 4 small children, but she doesn't have time to go to a gynecologist.

I sigh as I present her with her options. I explain the advantages and disadvantages of an IUD or the pill that contains progesterone. I offer her a prescription and promise to renew it without any problems, even over the phone. I tell her she should come for an examination when she can-alone, if possible. I explain the possible side effects and dangers, as well as the advantages. I give her some tips how to remember to take it every day and suggestions for what to do if she forgets a pill. I write everything down in medicolegal terms. Everything needs to be documented-just in case-including her current blood pressure.

The administrative director sends me a message that appears in a small window at the bottom of my computer screen: your 8:30, 8:40, 8:50, and 9:10 patients are waiting outside. How grateful I am that 
the 9:00 appointment is "saved for the doctor," but it doesn't really matter because it's 9:15.

\section{$10: 40$}

I get a phone call from Joseph's daughter. Joseph is a beloved patient who has visited our clinic on many occasions with a multitude of complaints. One time, when he complained about pain in his upper right stomach, I managed to overcome my thoughts to simply calm him down based on the dozens of imaging tests he underwent over the last year. Instead I referred him for a CT scan that showed metastases in the liver. He is suffering from advanced metastatic colon cancer and there seems to be no response to the aggressive treatment he's receiving at the hospital. "He's writhing in pain," she tells me from her office in Jerusalem. Her mother is caring for him but she confuses his medications and isn't able to give him the SOS doses of his narcotic medications. "I promise to come, at noon." I tell her. I call his home and instruct his wife to give him the blue pills. "MIR $15^{\prime \prime}$... she carefully reads to me, and I approve. I quickly phone the secretary: "Please clear my schedule for a home visit around 13:00 or 14:00, if possible...."

In the meantime, I race through 4 or 5 regular appointments. Simple illnesses: a gym approval, an army approval, prescription renewals with various recommendations for each such as blood tests, nurse follow-up, eye examinations, or weight loss, all the while trying to remain personal and connected to each patient in our several minutes together.

The coffee I made at 10:00 is cold and bland and I need a bathroom break. I carefully open the door, and 2 patients without appointments, who had promised the crowd waiting outside that they have "just a small question," ambush me in the hallway. An elderly lady leaning on her stick asks me to "just look" at her wound while the nurse changes her bandage; the nurse asks me to look over an ECG "in preparation for an operation" when I return. I push on towards my destination, the bathroom. I wash my hands thoroughly, glancing at the tired eyes facing me in the mirror, drying my hands under the hand dryer for the full 30 seconds, not wiping my hands on my clothes. Alas, a moment for myself. 10:43 and I need to get back to the room.

\section{$13: 20$}

I manage to sneak away for the home visit I promised to Joseph, the lovely man with colon cancer. The drive takes nearly 10 minutes and my next appointment is at 13:50. I allow myself to open the window and breathe in the fresh air, feel the wind on my face, and enjoy the green scenery. I know I am in for a depressing visit.
The patient lies groaning on the living room sofa. He's yellowish and his stomach is bloated. The medications are in a shoebox, mixed in with old medicines he no longer takes, other painkillers, old antibiotics. I can't find a laxative, and his wife can't recognize the SOS medicine, which is actually there in large amounts. I fix the box, throw out what isn't necessary, write down clear lists in Hebrew, mark them with a yellow highlighter, and quiz both husband and wife to make sure they understood my explanations. I squeeze in a few more minutes to ask how they're doing, warmly hugging the crying wife on the porch, calming her down, recommending that her husband doesn't overeat. I place a comforting hand on his, making sure he's relaxed and that he knows he can ask for help at any time. "I'm sorry, I must leave. I have patients waiting at the clinic," I tell them, sorry to leave them, but also glad to have time boundaries that protect me from getting overwhelmed with their sadness.

\section{3:55}

I park outside the clinic, praying the 13:50 patient won't be upset. Again I forget to swipe my card as "out on duty" and "back from duty." I hope it's not too important. I push the thought from my mind and wipe the crumbs from my shirt... once again I ate my sandwich while driving. I know it isn't healthy or hygienic, but I was hungry and there was no one there to see or scold.

\section{4:20 - Tammy Cohen, Age 32 Years}

Tammy: At first I was mad at the doctor: I told her about my headaches and my despair at her futile efforts, and asked for a CT and a referral to a neurologist, even though I already had a CT and went to a neurologist 3 months ago. I can't sleep at night and I have this choking feeling in my throat. I'm sure I have "something" horrible. The doctor asked me the same questions and checked me once more. She asked me to raise my arms and tickled my feet, shone her light into my eyes and saw my tears and defeated expression.

I saw her sigh and glance at her watch 10 minutes ago, but she caught herself in the act and asked if I've been sad lately and if I'm disinterested and unable to enjoy anything. I burst out crying, she placed a hand on mine and turned to the phone and asked the office to not allow any calls.

She listened silently and intently to everything I told her, despite my tears and runny nose. She acted like she had all the time in the world. She suggested I was depressed and I felt relieved that someone was finally ready to talk to me about it. She expressed hope and optimism and said she could help me. She accompanied me to the office and asked them to schedule 2 consecutive appointments for me for the next day.

I'm so lucky to have a doctor that has all the time in the world for me.... 


\section{5:45}

No more patients for today. At 16:00 I can swipe out and go home...only 10 prescription renewals, 2 phone calls to advise with various specialists concerning my patients, 4 messages for patients with irregular lab results and 1 request to repeat or change a treatment....

I usually enjoy this last hour when I can control my own time, choosing what to do first, calmly studying the patient's files and the lab results without any disturbances. Even if it takes another 30 or 60 minutes, $\mathrm{I}$ 'm ready to stay a little longer. This is my time to be totally devoted to my patients!

These feelings sour when I am called to the nurse's room for a child who was just brought in from the nearby nursery. I sew a cut on the child's chin and another patient calls to find out his lab results.

"I'm not here!" I call out to the secretary, who is also drained from a long exhausting day of measuring up to the patient's needs, as well as the bureaucratic and organizational demands of the system.

Ever since the installation of the clock, I am tempted once in a while, like on a day like today, to drop my pen and swipe my card at exactly 16:00, leaving all the extra work behind me. But once again my professional conscience takes over, and I sit another 30 minutes in the office, chanting to myself, mantra-like: "This is my time, these are my patients. I work for them. My work is a great honor and it isn't measured in time or money, but in heart and soul. I chose it, and I choose it again and again, each and every day...." Despite the pressures introduced by the clock, my allegiance will always be first and foremost to my patients, and I feel satisfied at the end of the day that I managed to find my way to remain faithful to them. At the end of the day, I succeed in measuring up to my own standards of care.

\section{$16: 30$}

I just swiped out. I'm finally in the car, on my way home. I clean the windshield, but it doesn't help the fuzziness is in my eyes. I remember I didn't enter the home visit into the computer. Oh, and I forgot to check on the dates of routine tests for the last 2 patients who asked for prescription renewals.

I wonder whether tomorrow I will once again succeed in ignoring the ticking of the clock and focus on the whisperings of my heart.

To read or post commentaries in response to this article, see it online at http://www.annfammed.org/content/11/5/477.

Key words: organization and administration; management of health care; chronic care: disease management / care management; community; public health; office management

Submitted September 12, 2012; submitted, revised, December 4, 2012, accepted December 28, 2012.

Acknowledgment: I thank Mrs Aya Rice for her assistance in reviewing and editing this manuscript.

\section{CORRECTION}

Ann Fam Med 2013;480. doi:10.1370/afm.1578.

Rabago D, Patterson JJ, Mundt M, et al. Dextrose prolotherapy for knee osteoarthritis: a randomized controlled trial. Ann Fam Med. 2013;11(3):229-237.

In Table 1, under Solution, the components for intra-articular 25\% dextrose erroneously contained $1 \%$ saline. There is no saline in the intra-articular injection, just the specified $5 \mathrm{~mL} 50 \%$ dextrose and $5 \mathrm{~mL} 1 \%$ lidocaine. 